\title{
Hastanede Çalışan Hemşirelerin İş Güvenliği
}

\section{Occupational Safety of Nurses Working at the Hospital}

\author{
Gülnur AKKAYA ${ }^{\mathrm{a}}$ Selma ATAY ${ }^{\mathrm{b}}$
}

\begin{abstract}
ÖZ Amaç: Bu çalışma hastanede çalışan hemşirelerin iş güvenliği durumlarının belirlenmesi amacıyla yapılmıştır. Yöntem: Kesitsel ve tanımlayıcı olarak yapılan bu çalışmanın örneklemini, devlet ve üniversite hastanesinde çalışan toplam 272 hemşire oluşturmuştur. Verilerin toplanmasında, hemşirelerin özelliklerini belirleyen form ve hastanede çalışan sağlık personeli için iş güvenliği ölçeği kullanılmıştır. Veriler SPSS 21.0 programında, sayı yüzde, ortalama kullanılarak değerlendirilmiştir. Bulgular: Araştırma bulgularına göre, hemşirelerin $\% 61.5$ ' $\mathrm{i}$ iş güvenliğine ilişkin tebliğden haberi olmadıklarını belirtmişlerdir. Hemşirelerin \% 61.5'içalışıkları kurumda iş güvenliği uzmanı olup olmadığını bilmediklerini, \%52.3'ü kurumlarında çalışan güvenliğine ilişkin komite olduğunu belirtmiştir. Hastanelerde iş güvenliğgi ölçeği toplam ve alt boyutlar bazında puan ortalamalarına bakıldığında ise; $2.16 \pm 0.98$ ve $3.96 \pm 1.48$ aralığında değişmiştir. Sonuç: Araştırmada, kurumlarda orta düzeyde bir iş güvenliğini sağlanabildiği bulunmuştur. Mesleki hastalıklar ve şikâyetler alt ölçeği, yönetsel destek ve yaklaşımlar alt ölçeği boyutunda ise, ortalamanın altında bulunmuştur.
\end{abstract}

Anahtar kelimeler: İş güvenliği, hastane, hemşire.

\begin{abstract}
Aim: This research was performed to determine occupational safety state of nurses working at hospitals. Methods: This research included a total of 272 nurses employed by state and university hospitals located in the center of Çanakkale. This is a descriptive research and the data were acquired between october and december 2015. Demographic forms and occupational health scale were used as data acquisition tool for health care professionals employed at hospitals. Data were evaluated, in SPSS 21.0 software program using expressed as mumbers, percentages, and means.Results: $61.5 \%$ of nurses stated that they were unaware of communique on occupational safety. $61.5 \%$ of nurses indicated that they did not know whether there was an occupational safety specialist at their organization, 52.3\% emphasized that there was a committee for employee safety at their organization. When we look the average scores of the total and sub-dimensions of occupational safety measures in hospitals; were spectively found between $2.16 \pm 0.98$ and 3.96 \pm 1.48 . Conclusion: According to research findings, nurses expressed that organizations ensured overall medium level of occupational safety. It fell below the average in the occupational diseases and complaints subscale and the administrative support and approaches subscale.
\end{abstract}

Keywords: Occupational safety, hospital, nurse.

\section{Giriş}

İş güvenliğinin amac1; çalışma ortamında iş sağlığ1 ve güvenliğinin sağlanması, mevcut sağlık, güvenlik şartlarının iyileştirilmesi için işverenlerin yanı sıra çalışanların görev, yetki, sorumluluk, hak ve görevlerininbelirlenmesidir. ${ }^{1}$ Başka bir deyişle iş güvenliği; iş ortamında sağlıklı, güvenli çalışma koşullarını oluşturmak, iş kazaları ve meslek hastalıklarını en alt düzeye indirmek, böylece de maddi ve manevi kayıpları önleyerek verimliliği artırmak şeklinde ifade edilebilir. İş güvenliği uygulamaları ile; çalışanın ,üretimin ve/veya hizmetin güvenliğini korumak, iş yeri güvenliğini sağlamak, ekolojik çevreye verilen zararı en alt düzeye indirmek mümkündür. ${ }^{2}$ Çalışanların motivasyonunun yükseltilmesinde güvenli çevrede önemli bir rol oynamaktadır. ${ }^{3}$ İşyerleri açısından da güvenli çalışma ortamının oluşturulması işletmenin rekabet konumunda üst seviyelere çıkmasını sağlamaktadır. Güvenlik açısından kötü şöhreti olan işyeri, nitelikli çalışan bulma konusunda zorlanacaktır. Ayrıca bu işyerlerinde verim düşecek ve işe gelmeme, devamsızlık, rapor kullanma gibi durumlar artarak maliyetler yükselecektir. ${ }^{4}$

Geliş Tarihi/Received: 12 -06- 2017-Kabul Tarihi/Accepted: 04-10-2017

aÇanakkale Onsekiz Mart Üniversitesi Sağlık Yüksekokulu Hemşirelik Bölümü, Terzioğlu Kampüsü /

Çanakkale, gulnurum@gmail.com, ORCID: 0000-0002-4176-2154

bÇanakkale Onsekiz Mart Üniversitesi Sağlık Yüksekokulu Hemşirelik Bölümü Terzioğlu Kampüsü /

Çanakkale, atayselma@ gmail.com, ORCID: 0000-0002-2068-1099

Sorumlu yazar /Correspondence: Yrd. Doç. Dr. Gülnur Akkaya Çanakkale Onsekiz Mart Üniversitesi Sağlık

Yüksekokulu Hemşirelik Bölümü, Terzioğlu Kampüsü / Çanakkale 
Hastaneler, hem sağliklı hem de hasta insanların bulunduğu, aynı zamanda otelcilik, restorant hizmetlerinin verildiği pek çok farklı meslek gurubundan çalışanın bulunduğu, eğitimlerin verildiği, öğrencilerin, ziyaretçilerin olduğu yüksek teknolojinin kullanıldığı karmaşı sistemli işyerleridir. ${ }^{5}$ Dolayısıyla hasta ve çalışan güvenliğinin sağlanması, eğitimlerin verilmesi, yöneticilerin gerekli tüm koruyucu önleyici tedbirleri alması, çalışanların bunları uygulaması çok önemlidir. Hastanelerde insan sağlığını tehdit eden, enfeksiyon hastalıkları, havalandırmanın yetersiz olmasından kaynaklanan solunum sistemi hastalıkları, kimyasallara maruz kalmaktan kaynaklanan dermatolojik problemler, radyasyona maruz kalma, ayakta iş görmekten dolayı kas iskelet sistemi hastalıkları, stresten meydana gelen psikolojik sorunlar, gastrointestinal sorunlar, tükenmişlik sendromu, psikolojik ve fiziksel şiddete maruz kalma gibi pek çok olumsuz faktörler sayılabilir. ${ }^{6-}$ ${ }^{10}$ Hastanelerde sağl1k işgücü içinde sayısal olarak büyük çoğunluğu oluşturan ayrıca hasta birey ve ailesiyle 7 gün 24 saat birlikte olan sağlık personeli olan hemşireler çeşitli sağlık ve güvenlik tehlikeleri ile karşı karşıya bulunmaktadır. Hemşireler işlerini kapalı alanlarda yapmaktadırlar, kapalı ortam koşullarından dolayı baş ağrısı, mide bulantısı, burun tıkanıklığı, uyuşukluk, baş dönmesi, genel solunum sıkıntısı ve performans düşüşü gibi nonspesifik, grip benzeri semptomların görülmesi ile ilişkilendirilebilir. ${ }^{11}$ Hastanede çalışma ortamının iyileştirilmesi; havalandırma, ergonomik koşullar, koruyucuların temin edilmesi gibi, güvenli ortamda çalışmalarını sağlayacak, bu da hem çalışanları hem de hasta bakım sonuçlarınıa pozitif yönde etki edecektir. Bizim çalışmamız, hemşirelerin çalışma ortam koşullarına dikkat çekilmesi açısından çok önemlidir. $\mathrm{Bu}$ çalışmada hastanede çalışan hemşirelerin iş güvenliği durumlarının belirlenmesi amaçlanmıştır.

\section{Yöntem}

Araştırmanın amacı ve türü: Tanımlayıcı olarak planlanan araştırmanın amacı, hastanede çalışan hemşirelerin iş güvenliği durumlarının belirlenmesidir.

Araştırma, Çanakkale ilinde bulunan üniversite ve devlet hastanesinde, Ekim-Aralık 2015 tarihleri arasında yapıldı. Araştırmanın evrenini üniversite ve devlet hastanesinde çalışan hemşireler, örneklemini ise Ekim Aralık 2015 tarihleri arasinda kendisine ulaşılabilen ve çalışmaya katılmayı kabul eden 272 hemşire oluşturmuştur. Devlet hastanesinde 390, tıp fakültesinde 67 toplam 457 hemşire vardır. Evrenin \%60'ına ulaşılmıştır. Dünya'da hemşirelerin veri toplama aracinı yanıtlama oranı \%40-\%50 arasındadır. Ülkemizde ise hemşirelerin anket formlarını yanıtlama oranının \% 55-65 arasında olduğu bilinmektedir. ${ }^{12}$

Veri toplama aracı olarak, demografik özellikler formu ve hastanede çalışan sağlık personeli için iş güvenliği ölçeği kullanılmıştır.

Hastanede Çalışan Sağllk Personeli İçin İş Güvenliği Ölçeği $i$ Ölçek, Öztürk ve Babacan $(2012$,a) tarafindan geliştirilmiş ve geçerlilik güvenirliği yapılmış toplam 45 madde ve mesleki hastalıklar ve şikâyetler (F1), sağlık taramas1 ve kayit sistemleri (F2), kazalar ve zehirlenmeler (F3), yönetsel destek ve yaklaşımlar (F4), malzeme, araç ve gereç denetimi (F5), koruyucu önlemler ve kurallar (F6), fiziksel ortam uygunluğu (F7) başlığında 7 alt faktörü bulunan likert tipi bir ölçektir. Maddeler "6" tamamen kat1lyorum ile " 1 " kesinlikle katılmiyorum arasında değerlendirilmektedir. Ölçek toplam puan aralığı 45270 'dir. Ölçekten alınan puan ölçek madde sayısına bölündüğünde puan aralığ 6 ile 1 arasında değer almaktadır. 6'ya yakın puan alınması hastanelerde iş güvenliğinin sağlandığgıı, 1'e yakın puan alınması iş güvenliğinin sağlanmadığını göstermektedir. Ölçeğin kapsam geçerliliği için CVI (Content Validity Index) $\% 92$, güvenirliği için madde-toplam puan korelasyon değerleri:0.47-0.74 ve Cronbach alpha hemşireler için 0.95 olarak belirtilmiştir. ${ }^{13}$ Çalışmamızda ölçeğin Cronbach alpha değeri 0.96 olarak bulundu.

Veriler, araştırmacılar tarafindan hafta içi, mesai saatleri içerisinde, servis hemşireleri ile yüz yüze görüşme tekniği kullanılarak topland1.

Elde elden veriler IBM SPSS Version 19 (Licensed Materials-Property of SPSS, Inc., an IBM Compaby) programinda analiz edildi. Verilerin değerlendirilmesinde; sayı, yüzde, ortalama kullanıldı.

Araştırma için Çanakkale Onsekiz Mart Üniversitesi Klinik Araştırmalar Etik Kurulu Başkanlığından 050.99-69 sayı ve 2014-06 karar numaras1 ile izin alınd1. Verilerin toplandığ 1 hastanenin bağlı olduğu hastane yönetiminden yazılı uygulama izni alınd. Araştırmaya katılmayı kabul eden hemşirelere çalışmanın amacı anlatılarak sözel onam alındı. 


\section{Bulgular}

Araştırma kapsamına alınan hemşirelerin \%77.1'i evli, \%87.4'ü kadın, \%78.6' sinın devlet hastanesinde çalıştığı, çalışanların yaş ortalaması $36.4 \pm 7.6$, kurumda çalışma yıl ortalaması $7.84 \pm 7.86$ ve mesleki deneyim süresi ortalamaları ise $15.5 \pm 8.3$ olarak bulundu.

Tablo 1. Araştırmaya Katılan Hemşirelerin İş̧ güvenliğine İlişkin Sorulara Verdikleri Yanitlar

\begin{tabular}{|c|c|c|}
\hline $\begin{array}{l}\text { İş güvenliğine İlişkin } \\
\text { Sorulara Verilen Yanıtlar }\end{array}$ & $\begin{array}{l}\text { Say1 } \\
(\mathrm{N})\end{array}$ & $\%$ \\
\hline \multicolumn{3}{|c|}{$\begin{array}{l}\text { Bulunduğunuz Kurumda iş Güvenliğine } \\
\text { İlişkin Komite var mı? }\end{array}$} \\
\hline Var & 137 & 52.3 \\
\hline Yok & 30 & 11.2 \\
\hline Bilmiyorum & 95 & 36.3 \\
\hline \multicolumn{3}{|c|}{$\begin{array}{l}\text { Bulunduğunuz Kurumda iş Güvenliği Uzmanı } \\
\text { Bulunuyor mu? }\end{array}$} \\
\hline Evet & 44 & 16.8 \\
\hline Hayır & 57 & 21.8 \\
\hline Bilmiyorum & 161 & 61.5 \\
\hline \multicolumn{3}{|c|}{$\begin{array}{l}\text { İş Güvenliğine İlişkin Tebliğden Haberiniz var } \\
\text { mı? }\end{array}$} \\
\hline Evet & 101 & 38.5 \\
\hline Hayır & 161 & 61.5 \\
\hline \multicolumn{3}{|c|}{$\begin{array}{l}\text { Çalışan güvenliğine ilişkin Verilen Eğitimden } \\
\text { Memnun Olma Durumu? }\end{array}$} \\
\hline Memnun & 128 & 48.9 \\
\hline Memnun değil & 134 & 51.1 \\
\hline
\end{tabular}

Tablo 1'de araştırmaya katılan hemşirelerin iş güvenliğine ilişkin sorulara verdikleri yanıtlar incelendiğinde hemşirelerin $\% 61.5$ ' $\mathrm{i}$ iş güvenliğine ilişkin tebliğden haberi olmadığını,\%61.5'i bulunduğu kurumda iş güvenliği uzmanı olup olmadığını bilmediğini, \%52.3’ü kurumlarında çalışan güvenliğine ilişkin komite olduğunu, \%51.1'i çalışan güvenliğine ilişkin verilen eğitimden memnun olmadığını belirtmiştir.

Araştırmaya dahil edilen hemşirelerin iş güvenliği ölçek ve alt ölçek puan ortalamaları Tablo 2'de verilmiştir. Tablo 2 incelendiğinde; toplam ölçek puan ortalamas1 $3.05 \pm 0.92$ iken, mesleki hastalıklar ve şikâyetler alt ölçeği puan ortalamas1 $2.16 \pm 0.98$, sağlık taramas1 ve kayıt sistemleri alt ölçeği puan ortalaması $3.33 \pm 1.36$, kazalar ve zehirlenmeler alt ölçeği puan ortalaması $3.51 \pm 1.49$, yönetsel destek ve yakla- şımlar alt ölçeği puan ortalamas1 2.54 \pm 1.11 , malzeme, araç ve gereç denetimi ölçeği puan ortalamas1 $3.71 \pm 1.46$, koruyucu önlemler ve kurallar alt ölçeği puan ortalaması $3.96 \pm 1.48 \mathrm{ve}$ fiziksel ortam uygunluğu alt ölçeği puan ortalaması $3.58 \pm 1.53$ olarak bulundu.

Tablo 2. Araştırmaya Dahil Edilen Hemşirelerin İş Güvenliği Ölçek ve Alt Ölçek Puan Ortalamalar1

\begin{tabular}{ll}
\hline Toplam ve alt boyutlar & Ort \pm SS \\
\hline $\begin{array}{l}\text { F1. Mesleki Hastalıklar ve } \\
\text { Şikayetler }\end{array}$ & $2,16 \pm 0.98$ \\
$\begin{array}{l}\text { F2. Sağlık Taraması ve Kayıt } \\
\text { Sistemi }\end{array}$ & $3,33 \pm 1.36$ \\
F3. Kazalar ve Zehirlenmeler & $3.51 \pm 1.49$ \\
F4.Yönetsel Destek ve & $2.54 \pm 1.11$ \\
Yaklaşımlar & \\
F5. Malzeme, Araç ve Gereç & $3.71 \pm 1.46$ \\
$\begin{array}{l}\text { Denetimi } \\
\text { F6. Koruyucu Önlemler ve }\end{array}$ & $3.96 \pm 1.48$ \\
Kurallar & \\
F7. Fiziksel Ortam Uygunluğu & $3.58 \pm 1.53$ \\
Toplam Ölçek & $3.05 \pm 0.92$ \\
\hline
\end{tabular}

\section{Tartışma}

Çalışmamızda hemşirelerin $\% 61.5$ ' $\mathrm{i}$ iş güvenliğine ilişkin tebliğden haberi olmadığını belirtmiştir. Öztürk ve ark $(2012, b)$ çalışmasında, hemşirelerin \%54'ü hasta ve çalışan güvenliğinin sağlanmasına ilişkin tebliği okuduğunu belirtirken \%46's1 okumadığını belirtmiştir. ${ }^{14}$

Çalışmamızda hemşirelerin \%51.1'i çalışan güvenliğine ilişkin verilen eğitimden memnun olmadığını belirtti (Tablo 1). Perthas ve ark. (2012) yaptıkları literatür taramasında, hemşireler çalıştıkları hastanede, güvenli hasta taşıma, güvenli enjeksiyon uygulama politika ve eğitiminin olmadığını ve bu nedenlerden dolayı daha fazla hemşirenin yaralanmaya maruz kaldığını belirtmiştir. ${ }^{4}$ Hemşirelerin iş güvenliği ölçeği toplam ve alt ölçekler bazında puan ortalamaları ise; toplam ölçek puan ortalaması $3.05 \pm 0.92$ iken mesleki hastalıklar ve şikâyetler alt ölçeği puan ortalaması $2.16 \pm 0.98$, sağlık taraması ve kayıt sistemleri alt ölçeği puan ortalamas1 $3.33 \pm 1.36$, kazalar ve zehirlenmeler alt ölçeği puan ortalamas $3.51 \pm 1.49$, yönetsel destek ve yaklaşımlar alt ölçeği puan ortalaması $2.54 \pm 1.11$, malzeme, araç ve gereç denetimi ölçeği puan ortalaması $3.71 \pm 1.46$, koruyucu 
önlemler ve kurallar alt ölçeği puan ortalaması $3.96 \pm 1.48$ ve fiziksel ortam uygunluğu alt ölçeği puan ortalamas1 $3.58 \pm 1.53$ olarak bulunmuştur. Ölçeğin değerlendirmesinde 6'ya yakın puan alınması hastanelerde iş güvenliğinin sağlandığını, 1'e yakın puan alınması iş güvenliğinin sağlanmadığını gösterdiği için toplamda orta düzeyde bir iş güvenliğini sağlandığını söylemek mümkündür. Ayrıca mesleki hastalıklar ve şikâyetler alt ölçeği, yönetsel destek ve yaklaşımlar alt ölçeği boyutunda ortalamanın altında olduğunu söyleyebiliriz.

Araştırma bulgularımıza benzer şekilde Öztürk ve ark $(2012, b)$ yaptığı çalışmada mesleki hastalıklar ve şikâyetler alt ölçeği puan ortalaması düşük bulunmuştur. Literatür incelendiğinde hemşirelerin, kas-eklem, damar hastalıkları, mide-bağırsak şikâyetleri, cilt, alerji, hepatit, üst solunum yolu enfeksiyonları, depresyon, kesici delici alet yaralanmalarına bağlı yumuşak doku travması gibi sorunları hastane de çalışan diğer meslek gruplarından daha fazla yaşadıkları görülmektedir., ${ }^{6,15-17}$ Benzer şekilde Pakowska ve ark. (2017) Polonya'da, yasal düzenlemelerden sonra tıbbi personelin yaralanmalarının kayıt altına alınması ile ilgili yaptıkları çalışmada, hemşirelerin yaralanma insidansının, hastanedeki diğer sağlık profesyonellerine göre anlamlı derecede yüksek ve yaralanmanın çoğunlukla iğne batmasından kaynaklandığını belirtmektedir. ${ }^{18}$ Clarke' 1 (2007) Amerika'da 2000 hemşire ile yaptığ çalışmada, 12 saat çalışan hemşirelerin, çalışma saati az olanlara oranla \%68 daha fazla iğne batmasına maruz kaldığını ve bu oranın çok yüksek olduğunubelirtmektedir. ${ }^{19}$ Hemşirelerin kendi isteklerinden ya da eleman eksikliğinden dolayı 12-24 saat çalışmaları sonucunda yaralanma risklerinin arttığı düşünülmektedir. Ayakta durma, ağır kaldırma, duruş bozukluklarından dolayı hemşirelerde, özellikle de ameliyathane ve yoğun bakım hemşirelerinde bel ağrıs1 sık görülmektedir. Literatür incelendiğinde bel ağrısından şikayet eden hemşirelerin oranı; Yunanistan'da \%75, Japonya'da \%71, Hollanda'da \%62, İtalya'da \%33-76, Türkiye'de $\% 65$ olarak görül-mektedir. ${ }^{20}$

Araştırma bulgularımıza benzer şekilde Öztürk ve ark (2012,b), Çelikkalp ve ark (2016) çalışmalarında da yönetsel destek ve yaklaşımlar alt ölçeği puan ortalaması düşük bulunmuştur. $^{14,21}$ Hasta ve iş güvenliğine yönelik tebliğ ile hasta ve sağlı çalışanlarının güvenliğinin sağlanmasına ilişkin hükümlerin yerine getirilmesinde hastane yönetimi hukuksal ve organizasyonel açıdan yükümlü tutulmaktadır. ${ }^{22}$ Fakat gerek çalışanlar ve gerekse hasta bakım kalitesinin artmasında yönetsel destek çok önemlidir. Stone ve Gershon (2006) çalışmalarında hemşirelerin çalışma koşullarının gözlenmesinin ve hastanelerde kurumsal iklimin geliştirilmesinin çalışanlarda düşük tükenmişlik ve hasta bakım kalitesinde artma gibi sistem çıktılarını artıracağını belirtmişlerdir. ${ }^{23}$ Benzer şekilde Gershan et all (2000) 481 hemşire ile yaptıkları çalışmada, hastane üst yöneticilerinin iş güvenliğini sağlamada ve konu ile ilgili eğitimlerde desteğinin düşük olması hemşirelerin iş kazalarına maruz kalmasını artırdığını belirtmişleridir. ${ }^{24}$ Clarke ve ark. (2002) yaptıkları çalışmada, iş yükünün fazla olması ve yönetimin iş güvenliği ile ilgili desteğinin düşük olması, hemşirelerde iğne batması ile yaralanmada ve hata yapma oranlarında artışa neden olduğunu belirtmiştir. ${ }^{25}$ Sağlık kurumlarının hasta güvenliğinin geliştirilmesi için birçok düzenleme yaptığı ve önlemler aldığı bilinmektedir. Kurumların hasta güvenliği gibi sağlık çalışanlarının da güvenliğini sağlayan önlem ve düzenlemeleri yapması gerekmektedir. Hemşirelerin güvenliğini artırmak için alınan önlemler daha sağlıklı ve etkin bir işgücü sağlayacağ gibi uzun vadede de hastaların yararına olacaktır. ${ }^{26}$

\section{Sonuç}

Araştırma bulgularına göre, kurumların toplamda orta düzeyde iş güvenliği sağladığı, mesleki hastalıklar ve şikâyetler, yönetsel destek ve yaklaşımlar alt ölçeğinde ise ortalamanın altında olduğu görüldü.

Sağlık kurumlarında önemli bir grubu oluşturan hemşirelere yönelik, iş güvenliğe ilişkin önlemlerin artırılması, hemşirelerin bilgilendirilmesine yönelik yasal düzenlemeler hakkında eğitimlerin bölüme yönelik olması önerilebilir. Hemşirelerin, iş kazalarının, hastalıklarının, raporlarının, aldıkları hizmet içi eğitimlerin kayıt altına alınması ve kurumda işyeri hemşiresinin bulundurulması önerilebilir.

Hemşirelerin iş sağl 1 ğ 1 , çalışma ortamı her zaman araştırılması gereken çok önemli ve güncel bir konudur. Bundan sonra da araştırmanın farklı illerde devlet, tıp fakültesi, özel, klinik ve dal hastanelerinde de yapılması önerilebilir.

Araştırmanın sınırlılıkları: $\mathrm{Bu}$ araştırma, bir ildeki üniversite ve devlet hastanesinde EkimAralık 2015 tarihlerinde çalışan izinli ve/veya 
raporlu olmayan hemşirelere ilişkin verileri yansitmaktadır.

\section{Kaynaklar}

1) İş Sağllğı ve Güvenliği Kanunu. Resmi Gazete 2012 .(Erişim tarihi: 17.05.2017) Erișim adresi: http://www.resmigazete.gov.tr/eskiler/2012/ 06/20120630-1.htm

2) Ceylan, H. Türkiye' deki iş kazalarının genel görünümü ve gelişmiş ülkelerle k1yaslanmas1 [Overview of JobAccidents in Turkey and Comparison with Developed Countries]International Journal of Engineering Researchand Development 2011;3(2):18-24.

3) Kıdak L, Aksaraylı M. Sağlık Hizmetlerinde Motivasyon Faktörleri [MotivationFactors in Healthcare Services] Celal Bayar Üniversitesi Sosyal Bilimler Dergisi 2009; 7(1): 75-94.

4) Sadullah Ö, İnsan kaynakları yönetimi [Human Resources Management]. 7.Bask1. İstanbul:İ.Ü. İşletme Fakültesi Yayınları (2877); 2015.p. 452-498.

5) Abdullah NAC, Spickett JT, Rumckev KB, Dhaliwal SS. Validity and reliability of the safety climate measurement in Malaysia. International Review Of Business Research Papers 2009; 5(3): 111-141.

6) AlçelikA, Deniz F, Yeşildal N, Mayda NS, Şerifi AB. AİBÜ tıp fakültesi hastanesinde görev yapan hemşirelerin sağlık sorunları ve yaşam alışkanlıklarının değerlendirilmesi [Health survey and life habits of nurses who work at the medical faculty hospital at AIBU]. TSK Koruyucu Hekimlik Bülteni [TAF Preventive Medicine Bulletin] 2005; 4(2): 55-65.

7) Waehrer G, Leigh JP, Miller TR. Cost of occupational injury and illness with in the health services sector. International Journal of Health Services. 2005;35(2):343-359.

8) Akkaya G.Avrupa Birliği ve Türk Mevzuatıaçısından sağlık kuruluşlarında iş sağlığ ${ }$, iş güvenliğ $\mathrm{i}$, meslek hastalıklarıve bir araştırma [Occupationalhealth, occupationalsafety, occupational diseases and a research in health institutions in terms of European Union and Turkish Legislation][Doktora tezi]. İstanbul Üniversitesi Sosyal Bilimler Enstitüsü [İstanbul University Institute of SocialSciences], İstanbul, Türkiye, 2007.
9) Bahçecik N,Öztürk H. The occupational safety and health in hospital from the point of nurses. Colleguim Antropologicum 2009; 33(4): 1205-14.

10) Rios KA, Barbosa DA, Belasco AGS. Evaluation of quality of life and depression in nursing technicians and nursing assistants. RevistaLatino-Americana de Enfermagem 2010; 18(3):413-20.

11) Sveinsdottir H. Self-assessed quality of sleep, occupational health, working environment, illness experience and job satisfaction of female nurses working different combination of shifts. Scandinavian Journal of CaringSciences 2006; 20(2):229-237.

12) Çınar ES. Farklı kuşaklardaki hemşirelerin çalışma ortamları algısı ile işten ve meslekten ayrilma niyetinin incelenmesi [Investigation of nurses from different generations' perception of work environments and their intentiontol eave the organızationand profession][Yüksek Lisans Tezi]. Dokuz Eylül Üniversitesi Sağlık Bilimleri Enstitüsü [Dokuz Eylül University Institute of Health Sciences], İzmir, Türkiye. 2016.

13) Öztürk H, Babacan E. (a) Bir ölçek geliştirme çalışması: hastanede çalışan sağlık personeli için iş güvenliği ölçeği [A Study in Scale Development: The Occupational Safety Scale (OSS) for Health Care Personnel Working in Hospital]. Hemşirelikte Eğitim ve Araştırma Dergisi 2012; 9(1): 36-42.

14) Öztürk H, Babacan E, Anahar ÖE. (b) Hastanede çalışan sağlık personelinin güvenliği [The occupational safety of health personnel in hospital].Gümüşhane Sağlık Bilimleri Dergisi [Gümüşhane University Journal of Health Sciences].2012; 1(4):252268.

15) Perhats C, Keough V, Fogarty J, Hughes NL, Kappelman JC, ScottM, Moretz J. Nonviolence related work place injurıes among emergency nurses in the united states: implications for improving safe practice, safe care. Journal Of Emergency Nursing 2012; 38(6):541-548.

16) Devebakan N. Özel Sağlık İşletmelerinde İş Sağlıği ve Güvenliği [Occupational Health and Safety in Private Health Care Organizations][Doktora Tezi]. Dokuz Eylül Üniversitesi Sosyal Bilimler Enstitüsü 
[Dokuz Eylül University Institute of Social Sciences],İzmir,Türkiye, 2007.

17) Sarıçam H. İş sağllğ 1 ve güvenliği kapsamında hemşirelerin karşılaştığı risk ve tehlikelerin iş stresi düzeyleri üzerine etkisi[Faced nurses under the occupational health and safety risk and hazards on theeffect of level of workstress][Yüksek lisans tezi], Dokuz Eylül Üniversitesi Sağlık Bilimleri Enstitüsü [Dokuz Eylül University Institute of Medical Sciences],İzmir, Türkiye, 2012.

18) Pakowska AG, Górajsk1 M,Szatko F.Did legal regulations change there porting frequency of sharp injuries of medical personnel? Study from 36 hospitals inprovince, Poland.International Journal of Occupational Medicine and Environmental Health 2018;31(1).

19) Clarke SP. Hospital work environments, nurse characteristics, and sharps injuries. American Journal of Infection Control 2007; 35(5):302-309.

20) Karahan A, Kav S, Abbasoğlu A,Doğan N.Low backpain: prevalence and associated risk factors among hospital staff. Journal of Advanced Nursing 2009;65(3):516-524.

21) Çelikkalp Ü, Varol SG, Keloğlu G, Bilgiç Ş. Hemşirelerin çalışma ortamlarında iş güvenliği uygulamalarını değerlendirmesi [The assessment of workplaces of nurses on occupationalsafety].TAF Preventive Medicine Bulletin 2016;15(5):408-413.

22) Hakeri H. Sağlık Çalışanı Güvenliği Ve Hukuksal Sorumluluk Health [Workers Safety and Legal Responsibilities] Sağlıkta Performans ve Kalite Dergisi] [Journal of HealthQualityandPerformance]. 2010;1(1) : 53-59.

23) Stone PW, Gershon RM. Nurse work environments and occupational safety in intensive care units. Policy, Politics\&Nursing Practise. 2006;7(4):240247.

24) Gershon RR, Karkashian CD, Grosch JW, Murphy LR, Escamilla-Cejudo A, Flanaqan PA,Bernacki E, Kasting C, Martin L. Hospital safety climate and its relation ship with safe work practices and workplace exposure incident. American Journal of Infection Control. 2000; 28(3):211-221.

25) Clarke SP, Rockett JL, Sloane MD, Aiken LH. Organizational climate, staffing, and safety equipment as predictors of needle stick injuries and near-misses in hospital nurses. American Journal of Infection Control. 2002;3(4):207-216.

26) Sunal N. Hemşirelerin iş güvenliği. Sağlık Düşüncesi ve Tip Kültürü Dergisi. AralıkOcak-Şubat 2014-2015; 33: 40-45. 